\title{
Analytical Study of Bending Characteristics of an Elastic Rectangular Plate using Direct Variational Energy Approach with Trigonometric Function
}

\author{
F. C. Onyeka ${ }^{1}$, B. O. Mama ${ }^{2 *}$ \\ ${ }^{1}$ Department of Civil Engineering, Edo State University Uzaire, Edo State, Nigeria \\ ${ }^{2}$ Department of Civil Engineering, University of Nigeria, Nsukka, Nigeria
}

\begin{abstract}
In this paper, an analytical three-dimensional (3D) bending characteristic of an isotropic rectangular thick plate with all edges simply supported (SSSS) and carrying uniformly distributed transverse load using the energy technique is presented. The three-dimensional constitutive relations which involves six stress components were used in the established, refined shear deformation theory to obtain a total potential energy functional. This theory obviates application of the shear correction factors for the solution to the problem. The governing equation of a thick plate was obtained by minimizing the total potential energy functional with respect to the out of plane displacement. The deflection functions which are in form of trigonometric were obtained as the solution of the governing equation. These deflection functions which are the product of the coefficient of deflection and shape function of the plate were substituted back into the energy functional, thereafter a realistic formula for calculating the deflection and stresses were obtained through minimizations with respect to the rotations and deflection coefficients. The values of the deflections and stresses obtained herein were tabulated and compared with those of previous 3D plate theory, refined plate theories and, classical plate theory (CPT) accordingly. It was observed that the result obtained herein varied more with those of CPT and RPT by $25.39 \%$ and $21.09 \%$ for all span-to-thickness ratios respectively. Meanwhile, the recorded percentage differences are as close as $7.17 \%$ for all span-to-thickness ratios, when compared with three dimensional plate analysis. This showed that exact 3D plate theory is more reliable than the shear deformation theory which are quite coarse for thick plate analysis
\end{abstract}

Keywords:

3D SSSS Plate;

Variational Technique;

Governing Equation;

Shear Correction Factors;

Deflection;

Trigonometric Displacement Functions.

\section{Article History:}

$\begin{array}{llll}\text { Received: } & 02 & \text { June } & 2021 \\ \text { Revised: } & 10 & \text { September } & 2021 \\ \text { Accepted: } & 14 & \text { October } & 2021 \\ \text { Published: } & 01 & \text { December } & 2021\end{array}$

\section{1- Introduction}

The applications of thick plate in engineering are numerous due to its flexible characteristics such as light weight and economy [1,2]. Classifications of plate can be based on the thickness (t) as; thin and thick plates [3]. The edges of plate can have different support conditions which can be fixed, simply supported, point, etc. The plates are mostly subjected to transverse and uniformly distributed loads acting in the middle plane of the plate. When a plate is subjected to such applied load at the boundary perpendicular to the mid-surface and distributed through the plate's thickness, the state of loading is called uniformly distributed lateral load [4]. Lateral loading causes a plate to bend or become elastically deformed. The bending and deformation of the plate caused by applying load can lead to failure of structure if not properly managed. To avoid failure of the plate, relatively more accurate and practical studies on bending analysis of plate are required.

\footnotetext{
* CONTACT: benjamin.mama@unn.edu.ng
}

DOI: http://dx.doi.org/10.28991/esj-2021-01320

(C) 2021 by the authors. Licensee ESJ, Italy. This is an open access article under the terms and conditions of the Creative Commons Attribution (CC-BY) license (https://creativecommons.org/licenses/by/4.0/). 
Rectangular plate ought to be analyzed as a three-dimensional (3-D) element, however, the intricacies involved made many scholars to introduce approximations. One major approximation is the classical plate theory (CPT). The CPT was formulated by Kirchhoff (1850) [5, 6] and was applied by Timoshenko \& Woinowsky-krieger (1970) and Leissa (1973) $[4,7]$ for the analysis of plates and shells. The CPT, which does not address shear deformation transversely as seen in the thin plate analysis. It is based on the assumption that the deformation line remains perpendicular before and after deformation. Due to the non-inclusion of transverse shear strains or deformation in CPT, it has been found to be inadequate in the analysis of thick plates [5]. To address the shortfall in the CPT, the researchers formulated the refined plate theory (RPT).

The RPT is a plate theory that considered the effect of transverse shear deformation in the analysis. They include; the first order shear deformation theory (FSDT) [8-10], second order shear deformation theory (SSDT). Mama et al. (2017) and Zenkour (2003) [11, 12] studied the effect of transverse shear deformation on the bending elastic plate using Mindlin plate theory (FSDT). The added a complication known as a shear correction factor to account for the shear deformation effect in the plate.

To consider the effect transverse shear deformation in the plate analysis without shear correction factor, a higher order shear deformation theory (HSDT) was developed which achieved a realistic variation of transverse shear stress from top to bottom of the plate [13-15], in the analysis of plates, using different functions like: hyperbolic, exponential or polynomial functions. The refined plate theory, assumed that the normal strain and stress along the thickness axis of the plate is negligible. This assumption makes the theory inconsistent and can be regarded as a 2-D or an incomplete 3-D plate theory.

Not much study has been carried out by earlier scholars on rectangular thick plate analysis using the 3-D plate theory. Some of them are for the numerical analysis of plate like finite element method, finite strip method, etc. [16-18]. The numerical analysis is limited as the only give approximate solution and its inability to determine the values of stresses and displacement at any point of the plate is shown. However, Uymaz and Aydogdu (2013) and Pagano (1970) [19, 20] performed a 3-D analysis of solid rectangular plate to determine the stress element that induces deformation in the plate structure by employing the Ritz approach with assumed displacement functions. It was discovered that by assuming the displacement function, the result of the 3-D plate analysis will yield an approximate solution.

Ibearugbulem et al. and Onyeka \& Edozie (2021) [21, 22] utilized the analytical approach to get the exact polynomial displacement function from the governing equation. They did not apply trigonometric function which gives closer form solution than polynomial whose exact function tends to infinity [23].

The two-dimensional theories (incomplete three-dimensional theory) can be derived by making suitable assumptions concerning the kinematics of deformation or the state of stress through the thickness of the plate [20]. From the previous studies in the literature, it is found that 2-D theory or 3-D theory with an approximate solution was used for the analysis, but for a typical thick plate analysis, a typical 3-D plate theory which will yield an exact solution is required. A typical 3-D plate theory involves all the six strains and stress components, unlike the FSDT and HSDT plate theory which assumed that the strain normal to the x-y plane $\left(\sigma_{z}\right)$ is so small that it can be neglected. The major limitation of the 2-D plate analysis is the understating of stresses in the member which makes its result unreliable. Furthermore, it is recorded that both Mindlin's theories (FSDT) and other higher shear deformation incomplete three-dimensional analysis are approximations of the elasticity three-dimensional equilibrium equations and cannot be reliable for thick plate analysis. More so, the 3-D theory with polynomial displacement function will not give an exact solution which makes it not dependable for analysis of all categories of plate (thin, moderately thick and thick plate). This gap in the literature is worth filling.

The present study is trying to present an analytical improved plate theory and applied in the three-dimensional bending analysis of a plate under uniformly distributed load using trigonometric displacement functions. The aim of this work is to study the exact bending characteristics of an elastic rectangular plate subjected to a plate with simply support in all edges using the direct variation technique. This model can be trustworthy in the analysis of any category of rectangular plate to obtain the normal stresses that may occur in the direction of the $\mathrm{x}, \mathrm{y}$ and $\mathrm{z}$ co-ordinates due to applied load on the plate. Hence, the shear stress along the $x-y$ axis, $x-z$ axis and $y-z$ axis that are induced due to the transverse load on the plate will be determined. Furthermore, the deflection and the in-plane displacement along $\mathrm{x}$ and $\mathrm{y}$ axis of the plate will also be measured and presented.

The limitations and constraints of this study includes the followings:

- The mid plane of the plate is flat and not inclined.

- The issue of oscillation of the plate due to vibration and buckling of the plate is not considered.

- Varying load, patch load and peak load is not debated.

- Experiment were not conducted on the properties of the materials used.

- Effect of torsion due to warping of the plate is neglected. 


\section{2- Research Methodology}

The processes involved in the formulation of kinematics relations and three-dimensional constitutive relations using the elastic static theory of isotropic plate. The strain energy and external work done on the plate, the total potential energy equation of a thick rectangular plate using energy expression was developed from the 3-D constitutive relations and kinematic deformation. The governing equations were derived and solved in terms of trigonometric shape function to get the exact deflection function and its relation to rotations. Thereafter, the total potential energy equation was minimized using the function of rotation and deflection to obtain their coefficient and stresses in the plate. Figure 1 shows a flowchart to the article analysis procedure as presented in the research methodology.

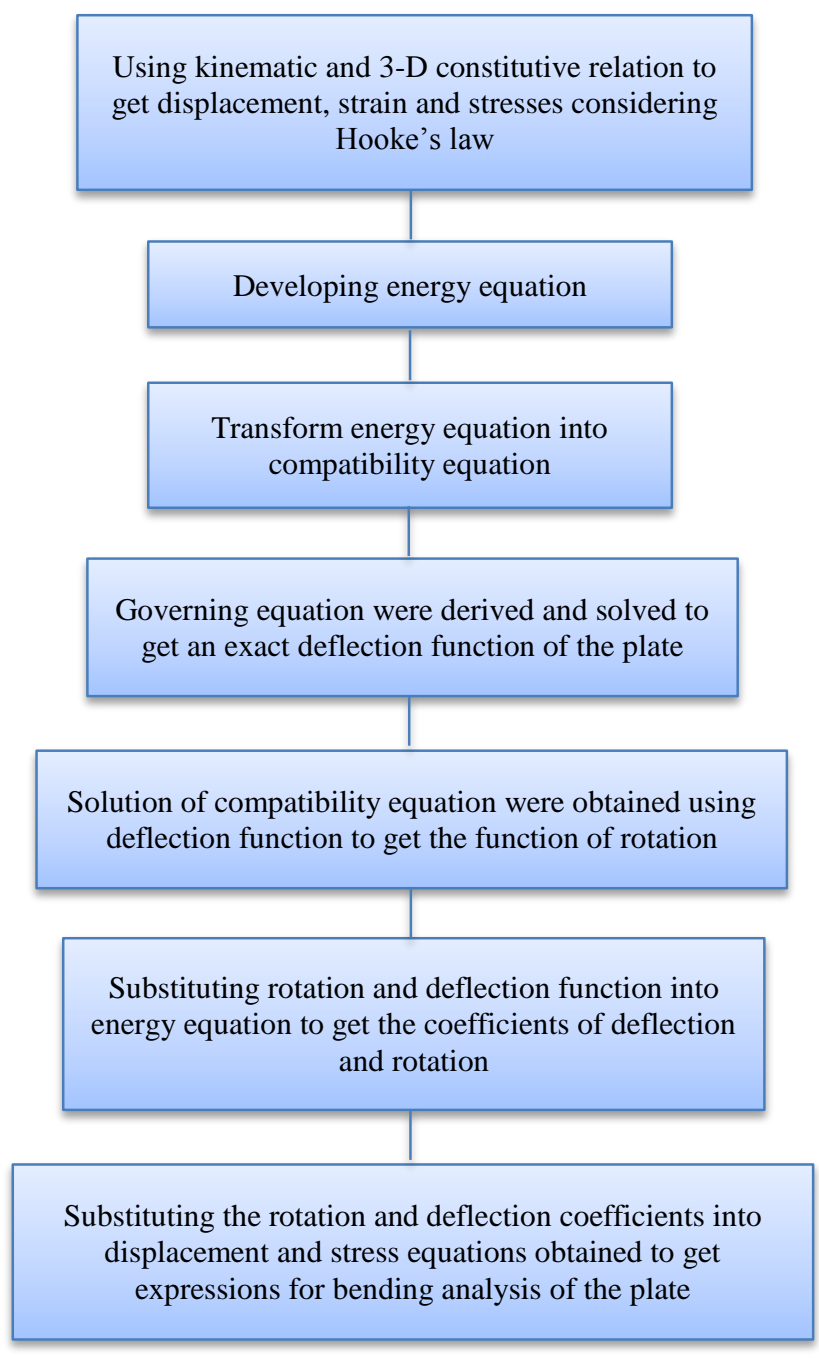

Figure 1. Flowchart to the article analysis procedure as presented in the research methodology.

\section{2-1-Basic Assumptions}

The basic assumptions for three dimensional analyses of refined shear deformation thick continuum plate of small deflection theorems include the following:

- The plate material is elastic, homogenous and isotropic.

- The middle surface of the flat plate never stretches nor compresses before, during or after bending.

- A flat $x-z$ or $y-z$ section, which is normal to middle $x-y$ plane before bending shall no longer remain normal to the middle $x-y$ surface after bending.

\section{2-2-Kinematics}

This is unlike dynamics, which is the branch of mechanics that deals only with the forces that cause movement of bodies. In kinematics, displacements and strains are considered. The displacement field includes the displacements along $\mathrm{x}, \mathrm{y}$ and z-axes: $\mathrm{u}, \mathrm{v}$ and $\mathrm{w}$ respectively. After bending of the plate the $\mathrm{x}-\mathrm{z}$ section and $\mathrm{y}-\mathrm{z}$ section, which are initially normal to the $x-y$ plane before bending go off normal to the $x-y$ plane as seen in Figure 2. 
Our formulation of the energy equation for the stability analysis thick rectangular plate under compressive load will be based on Figure 2, Figure 3 and assumptions made in the previous section. As shown in Figure 2, the spatial dimensions of the plate along $\mathrm{x}, \mathrm{y}$ and $\mathrm{z}$-axes are $\mathrm{a}, \mathrm{b}$ and $\mathrm{t}$ respectively.

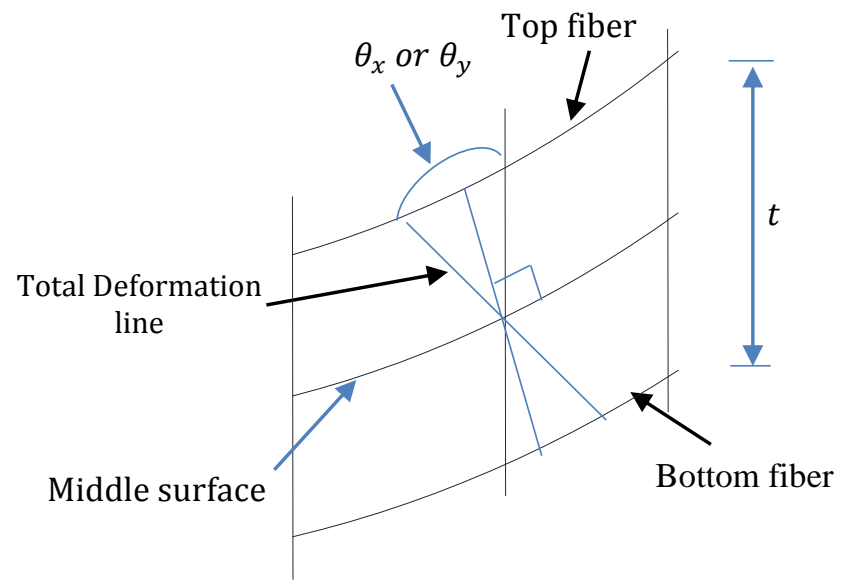

Figure 2. Rotation of $x-z$ (or $y-z)$ section after bending.

As shown in the Figure 3, the displacement field includes the displacements along $\mathrm{x}, \mathrm{y}$ and $\mathrm{z}$-axes: u, v and w respectively. The displacement and slope along the $\mathrm{x}$ axis and $\mathrm{y}$ axis are mathematically expressed as:

$\theta_{x}=\frac{\partial u}{\partial z}$
$\theta_{y}=\frac{\partial v}{\partial z}$

Considering assumption iii and Figure 2, $\mathrm{F}$ as used is a function of $\mathrm{z}$ coordinate. Thus, the in-plane displacements; $\mathrm{u}$ and $\mathrm{v}$ as presented in the Equation 2 and 3 are further defined using trigonometric relations for small angles as:

$u=z \theta_{x}$

$v=z \theta_{y}$

where: $u$ and $v$ are the in-plane displacement along $\mathrm{x}$-axis and y axis respectively, $\theta_{x}$ and $\theta_{y}$ are the shear deformation slope along $\mathrm{x}$ axis and $\mathrm{y}$ axis, and $F$ represents the shear deformation profile.

Taking the non-dimensional form of coordinates to be $\mathrm{R}=\mathrm{x} / \mathrm{a}, \mathrm{Q}=\mathrm{y} / \mathrm{b}$ and $\mathrm{S}=\mathrm{z} / \mathrm{t}$ corresponding to $\mathrm{x}, \mathrm{y}$ and $\mathrm{z}$-axes respectively, the six strain components in terms of non-dimensional coordinates are written as:

$$
\begin{aligned}
& \varepsilon_{x}=\frac{S t}{a} \frac{d \theta_{x}}{d R} \\
& \varepsilon_{y}=\frac{S t}{a \beta} \frac{d \theta_{y}}{d Q} \\
& \varepsilon_{z}=\frac{1}{t} \frac{d w}{d S} \\
& \gamma_{x y}=\frac{S t}{a \beta} \frac{d \theta_{x}}{d Q}+\frac{S t}{a} \frac{d \theta_{y}}{d R} \\
& \gamma_{x z}=\theta_{x}+\frac{1}{a} \frac{d w}{d R} \\
& \gamma_{y z}=\theta_{y}+\frac{1}{a \beta} \frac{d w}{d Q}
\end{aligned}
$$

where: $\varepsilon_{x}, \varepsilon_{y}$ and $\varepsilon_{z}$ are normal strain along $\mathrm{x}$ axis, $\mathrm{y}$ axis and $\mathrm{z}$ axis respectively, $\gamma_{x y}, \gamma_{x z}$ and $\gamma_{y z}$ represents the shear strain in the plane parallel to the $\mathrm{x}-\mathrm{y}, \mathrm{x}-\mathrm{z}$ and $\mathrm{y}-\mathrm{z}$ plane.

\section{2-3-Constitutive Relations}

By considering the stresses causing the body movements, the generalized Hooke's law principle was applied to get the three dimensional constitutive relation as given:

$$
\left[\begin{array}{c}
\varepsilon_{x} \\
\varepsilon_{y} \\
\varepsilon_{z} \\
\gamma_{x z} \\
\gamma_{y z} \\
\gamma_{x y}
\end{array}\right]=\frac{1}{E}\left[\begin{array}{cccccc}
1 & -\mu & -\mu & 0 & 0 & 0 \\
-\mu & 1 & -\mu & 0 & 0 & 0 \\
-\mu & -\mu & 1 & 0 & 0 & 0 \\
0 & 0 & 0 & 2(1+\mu) & 0 & 0 \\
0 & 0 & 0 & 0 & 2(1+\mu) & 0 \\
0 & 0 & 0 & 0 & 0 & 2(1+\mu)
\end{array}\right]\left[\begin{array}{c}
\sigma_{x} \\
\sigma_{y} \\
\sigma_{z} \\
\tau_{x z} \\
\tau_{y z} \\
\tau_{x y}
\end{array}\right]
$$


Modulus of elasticity and Poisson's ratios are denoted with E and $\mu$ respectively. Substituting Equations 5 to 10 into Equation 11 and writing the equations of the six stress components one by one in term of the displacements gives:

$$
\begin{aligned}
& \sigma_{x}=\frac{E t s}{(1+\mu)(1-2 \mu) a}\left[(1-\mu) \cdot \frac{\partial \theta_{x}}{\partial R}+\frac{\mu}{\beta} \cdot \frac{\partial \theta_{y}}{\partial Q}+\frac{\mu a}{s t^{2}} \cdot \frac{\partial w}{\partial S}\right] \\
& \sigma_{y}=\frac{E t s}{(1+\mu)(1-2 \mu) a}\left[\mu \cdot \frac{\partial \theta_{x}}{\partial R}+\frac{(1-\mu)}{\beta} \cdot \frac{\partial \theta_{y}}{\partial Q}+\frac{\mu a}{s t^{2}} \cdot \frac{\partial w}{\partial s}\right] \\
& \sigma_{z}=\frac{E t s}{(1+\mu)(1-2 \mu) a}\left[\mu \cdot \frac{\partial \theta_{x}}{\partial R}+\frac{\mu}{\beta} \cdot \frac{\partial \theta_{y}}{\partial Q}+\frac{(1-\mu) a}{s t^{2}} \cdot \frac{\partial w}{\partial S}\right] \\
& \tau_{x y}=\frac{E(1-2 \mu) t s}{2(1+\mu)(1-2 \mu) a} \cdot\left[\frac{1}{\beta} \frac{\partial \theta_{x}}{\partial Q}+\frac{\partial \theta_{y}}{\partial R}\right] \\
& \tau_{x z}=\frac{E(1-2 \mu) t s}{2(1+\mu)(1-2 \mu) a} \cdot\left[\frac{a}{t s} \theta_{x}+\frac{1}{t s} \frac{\partial w}{\partial R}\right] \\
& \tau_{y z}=\frac{E(1-2 \mu) t s}{2(1+\mu)(1-2 \mu) a} \cdot\left[\frac{a}{t s} \theta_{y}+\frac{1}{\beta t s} \frac{\partial w}{\partial Q}\right]
\end{aligned}
$$

\section{2-4-Strain Energy}

Strain energy is the average of the product of stress and strain indefinitely summed up within the spatial domain of the body. This mathematically expressed as:

$$
U=\frac{a b t}{2} \int_{0}^{1} \int_{0}^{1} \int_{-0.5}^{0.5}\left(\sigma_{x} \varepsilon_{x}+\sigma_{y} \varepsilon_{y}+\sigma_{z} \varepsilon_{z}+\tau_{x y} \gamma_{x y}+\tau_{x z} \gamma_{x z}+\tau_{y z} \gamma_{y z}\right) d R d Q d S
$$

Substituting Equations 5 to 10 and Equations 12 to 17 into Equation 18, simplifying and carrying out the integration of the outcome with respect to $\mathrm{S}$ considering that $\mathrm{S}=\mathrm{z} / \mathrm{t}$ gives:

$$
\begin{aligned}
& U=\frac{D^{*} a b}{2 a^{2}} \int_{0}^{1} \int_{0}^{1}\left[(1-\mu)\left(\frac{\partial \theta_{s x}}{\partial R}\right)^{2}+\frac{1}{\beta} \frac{\partial \theta_{s x}}{\partial R} \cdot \frac{\partial \theta_{s y}}{\partial Q}+\frac{(1-\mu)}{\beta^{2}}\left(\frac{\partial \theta_{s y}}{\partial Q}\right)^{2}+\frac{(1-2 \mu)}{2 \beta^{2}}\left(\frac{\partial \theta_{s x}}{\partial Q}\right)^{2}+\frac{(1-2 \mu)}{2}\left(\frac{\partial \theta_{s y}}{\partial R}\right)^{2}+\right. \\
& \left.\frac{6(1-2 \mu)}{t^{2}}\left(a^{2} \theta_{s x}{ }^{2}+a^{2} \theta_{s y}{ }^{2}+\left(\frac{\partial w}{\partial R}\right)^{2}+\frac{1}{\beta^{2}}\left(\frac{\partial w}{\partial Q}\right)^{2}+2 a \cdot \theta_{s x} \frac{\partial w}{\partial R}+\frac{2 a \cdot \theta_{s y}}{\beta} \frac{\partial w}{\partial Q}\right)+\frac{(1-\mu) a^{2}}{t^{4}}\left(\frac{\partial w}{\partial S}\right)^{2}\right] d R d Q
\end{aligned}
$$

Where:

$$
D^{*}=\frac{E t^{3}}{12(1+\mu)(1-2 \mu)}=D \frac{(1-\mu)}{(1-2 \mu)}
$$

\section{2-5- Energy Equation Formulation}

Total Energy Expression be the algebraic summation of strain energy (U) and external work (E). That is:

$\Pi=\mathrm{U}-\mathrm{E}$

The potential energy for the plate with uniformly distributed load is given as:

$$
E=-\int_{0}^{a} \int_{0}^{b} q w(x, y) \partial x \partial y
$$

where; the symbol $\mathrm{w}(\mathrm{x}, \mathrm{y})$ denotes the deflection in $\mathrm{x}$ and $\mathrm{y}$ direction, and $\mathrm{q}$ denotes the uniformly distributed load;

$$
E=a b q \int_{0}^{1} \int_{0}^{1} w d R d Q
$$

where, the symbol $\mathrm{h}$ denotes the shape function of the plate, while; $\mathrm{a}$ and $\mathrm{b}$ is the length and breadth of the plate Substituting Equations 19 and 22 into Equation 21 gives:

$$
\begin{aligned}
& \Pi=\frac{D^{*} a b}{2 a^{2}} \int_{0}^{1} \int_{0}^{1}\left[(1-\mu)\left(\frac{\partial \theta_{s x}}{\partial R}\right)^{2}+\frac{1}{\beta} \frac{\partial \theta_{s x}}{\partial R} \cdot \frac{\partial \theta_{s y}}{\partial Q}+\frac{(1-\mu)}{\beta^{2}}\left(\frac{\partial \theta_{s y}}{\partial Q}\right)^{2}+\frac{(1-2 \mu)}{2 \beta^{2}}\left(\frac{\partial \theta_{s x}}{\partial Q}\right)^{2}+\frac{(1-2 \mu)}{2}\left(\frac{\partial \theta_{s y}}{\partial R}\right)^{2}+\frac{6(1-2 \mu)}{t^{2}}\left(a^{2} \theta_{s x}{ }^{2}+\right.\right. \\
& \left.\left.a^{2} \theta_{s y}{ }^{2}+\left(\frac{\partial w}{\partial R}\right)^{2}+\frac{1}{\beta^{2}}\left(\frac{\partial w}{\partial Q}\right)^{2}+2 a \cdot \theta_{s x} \frac{\partial w}{\partial R}+\frac{2 a \cdot \theta_{s y}}{\beta} \frac{\partial w}{\partial Q}\right)+\frac{(1-\mu) a^{2}}{t^{4}}\left(\frac{\partial w}{\partial S}\right)^{2}\right] d R d Q-\int_{0}^{1} \int_{0}^{1} q w a b \partial R \partial Q
\end{aligned}
$$

This gives:

$$
\begin{aligned}
& \Pi=\frac{D^{*} a b}{2 a^{2}} \int_{0}^{1} \int_{0}^{1}\left[(1-\mu)\left(\frac{\partial \theta_{s x}}{\partial R}\right)^{2}+\frac{1}{\beta} \frac{\partial \theta_{s x}}{\partial R} \cdot \frac{\partial \theta_{s y}}{\partial Q}+\frac{(1-\mu)}{\beta^{2}}\left(\frac{\partial \theta_{s y}}{\partial Q}\right)^{2}+\frac{(1-2 \mu)}{2 \beta^{2}}\left(\frac{\partial \theta_{s x}}{\partial Q}\right)^{2}+\frac{(1-2 \mu)}{2}\left(\frac{\partial \theta_{s y}}{\partial R}\right)^{2}+\frac{6(1-2 \mu)}{t^{2}}\left(a^{2} \theta_{s x}{ }^{2}+\right.\right. \\
& \left.\left.a^{2}{\theta_{s y}}^{2}+\left(\frac{\partial w}{\partial R}\right)^{2}+\frac{1}{\beta^{2}}\left(\frac{\partial w}{\partial Q}\right)^{2}+2 a \cdot \theta_{s x} \frac{\partial w}{\partial R}+\frac{2 a \cdot \theta_{s y}}{\beta} \frac{\partial w}{\partial Q}\right)+\frac{(1-\mu) a^{2}}{t^{4}}\left(\frac{\partial w}{\partial S}\right)^{2}-\frac{2 q a^{4} w}{D^{*}}\right] d R d Q
\end{aligned}
$$




\section{2-6-Governing Equation}

The exact solution of the governing equation in trigonometric form is obtained according to Onyeka et al. (2021) [24] by minimizing the total potential energy functional with respect to deflection to give the exact equation of deflection, shear deformation slope in $\mathrm{x}$-axis and shear deformation slope in y-axis as presented in Equations 26 to 28 respectively: $w=\left[\begin{array}{llll}1 & R & \operatorname{Cos}\left(c_{1} R\right) & \operatorname{Sin}\left(c_{1} R\right)\end{array}\right]\left[\begin{array}{l}a_{0} \\ a_{1} \\ a_{2} \\ a_{3}\end{array}\right] \cdot\left[\begin{array}{lll}1 & Q & \operatorname{Cos}\left(c_{1} Q\right) \operatorname{Sin}\left(c_{1} Q\right)\end{array}\right]\left[\begin{array}{l}b_{0} \\ b_{1} \\ b_{2} \\ b_{3}\end{array}\right]$

$\theta_{x}=\frac{c}{a} \cdot \Delta_{0} \cdot\left[\begin{array}{lll}1 & c_{1} \operatorname{Sin}\left(c_{1} R\right) & c_{1} \operatorname{Cos}\left(c_{1} R\right)\end{array}\right]\left[\begin{array}{l}a_{1} \\ a_{2} \\ a_{3}\end{array}\right] \cdot\left[\begin{array}{lll}1 & Q & \operatorname{Cos}\left(c_{1} Q\right) \operatorname{Sin}\left(c_{1} Q\right)\end{array}\right]\left[\begin{array}{l}b_{0} \\ b_{1} \\ b_{2} \\ b_{3}\end{array}\right]$

$\theta_{y}=\frac{c}{a \beta} \cdot \Delta_{0} \cdot\left[\begin{array}{llll}1 & R & \operatorname{Cos}\left(c_{1} R\right) \operatorname{Sin}\left(c_{1} R\right)\end{array}\right]\left[\begin{array}{l}a_{0} \\ a_{1} \\ a_{2} \\ a_{3}\end{array}\right] \cdot\left[\begin{array}{lll}1 & c_{1} \operatorname{Sin}\left(c_{1} Q\right) & c_{1} \operatorname{Cos}\left(c_{1} Q\right)\end{array}\right]\left[\begin{array}{l}b_{1} \\ b_{2} \\ b_{3}\end{array}\right]$

Let:

$$
\begin{aligned}
& w=A_{1} \cdot h \\
& \theta_{x}=\frac{A_{2}}{a} \cdot \frac{\partial h}{\partial R} \\
& \theta_{y}=\frac{A_{3}}{a \beta} \cdot \frac{\partial h}{\partial Q}
\end{aligned}
$$

Where; $A_{1}, A_{2}$ and $A_{3}$ denotes deflection coefficient, coefficient of slope in $\mathrm{x}$ axis and y axis respectively.

Substituting Equation 29, 30 and 31 into 25, gives:

$\Pi=\frac{D^{*} a b}{2 a^{4}} \int_{0}^{1} \int_{0}^{1}\left[(1-\mu) A_{2}{ }^{2}\left(\frac{\partial^{2} h}{\partial R^{2}}\right)^{2}+\frac{1}{\beta^{2}}\left[A_{2} \cdot A_{3}+\frac{(1-2 \mu) A_{2}{ }^{2}}{2}+\frac{(1-2 \mu) A_{3}{ }^{2}}{2}\right]\left(\frac{\partial^{2} h}{\partial R \partial Q}\right)^{2}+\frac{(1-\mu) A_{3}{ }^{2}}{\beta^{4}}\left(\frac{\partial^{2} h}{\partial Q^{2}}\right)^{2}+\right.$
$\left.6(1-2 \mu)\left(\frac{a}{t}\right)^{2}\left(\left[{A_{2}}^{2}+{A_{1}}^{2}+2 A_{1} A_{2}\right] \cdot\left(\frac{\partial h}{\partial R}\right)^{2}+\frac{1}{\beta^{2}} \cdot\left[{A_{3}}^{2}+A_{1}{ }^{2}+2 A_{1} A_{3}\right] \cdot\left(\frac{\partial h}{\partial Q}\right)^{2}\right)-\frac{2 q a^{4} h A_{1}}{D^{*}}\right] d R d Q$

Writing Equation 32 in more symbolized form gives:

$\Pi=\frac{D^{*} a b}{2 a^{4}}\left[(1-\mu) A_{2}{ }^{2} k_{x}+\frac{1}{\beta^{2}}\left[A_{2} \cdot A_{3}+\frac{(1-2 \mu) A_{2}{ }^{2}}{2}+\frac{(1-2 \mu) A_{3}{ }^{2}}{2}\right] k_{x y}+\frac{(1-\mu) A_{3}{ }^{2}}{\beta^{4}} k_{y}+6(1-2 \mu)\left(\frac{a}{t}\right)^{2}\left(\left[A_{2}{ }^{2}+A_{1}{ }^{2}+\right.\right.\right.$ $\left.\left.\left.2 A_{1} A_{2}\right] \cdot k_{z}+\frac{1}{\beta^{2}} \cdot\left[A_{3}^{2}+A_{1}^{2}+2 A_{1} A_{3}\right] \cdot k_{2 z}\right)-\frac{2 q a^{4} k_{h} A_{1}}{D^{*}}\right]$

Where:

$$
\begin{aligned}
& k_{x}=\int_{0}^{1} \int_{0}^{1}\left(\frac{\partial^{2} h}{\partial R^{2}}\right)^{2} d R d Q \\
& k_{x y}=\int_{0}^{1} \int_{0}^{1}\left(\frac{\partial^{2} h}{\partial R \partial Q}\right)^{2} d R d Q \\
& k_{y}=\int_{0}^{1} \int_{0}^{1}\left(\frac{\partial^{2} h}{\partial Q^{2}}\right)^{2} d R d Q \\
& k_{z}=\int_{0}^{1} \int_{0}^{1}\left(\frac{\partial h}{\partial R}\right)^{2} d R d Q \\
& k_{2 z}=\int_{0}^{1} \int_{0}^{1}\left(\frac{\partial h}{\partial Q}\right)^{2} d R d Q ; k_{h}=\int_{0}^{1} \int_{0}^{1} h \cdot d R d Q
\end{aligned}
$$

Minimizing Equation 33 with respect to $A_{2}$ gives:

$$
\frac{\partial \Pi}{\partial A_{2}}=(1-\mu) A_{2} k_{x}+\frac{1}{2 \beta^{2}}\left[A_{3}+A_{2}(1-2 \mu)\right] k_{x y}+6(1-2 \mu)\left(\frac{a}{t}\right)^{2}\left[A_{2}+A_{1}\right] \cdot k_{z}=0
$$

Minimizing Equation 33 with respect to $A_{3}$ gives:

$$
\frac{\partial \Pi}{\partial A_{2}}=\frac{(1-\mu) A_{3}}{\beta^{4}} k_{y}+\frac{1}{2 \beta^{2}}\left[A_{2}+A_{3}(1-2 \mu)\right] k_{x y}+\frac{6}{\beta^{2}}(1-2 \mu)\left(\frac{a}{t}\right)^{2}\left(\left[A_{3}+A_{1}\right] \cdot k_{2 z}\right)=0
$$

Rewriting Equations 34 and 35 gives: 


$$
\begin{aligned}
& {\left[(1-\mu) k_{x}+\frac{1}{2 \beta^{2}}(1-2 \mu) k_{x y}+6(1-2 \mu)\left(\frac{a}{t}\right)^{2} k_{z}\right] A_{2}+\left[\frac{1}{2 \beta^{2}} k_{x y}\right] A_{3}=\left[-6(1-2 \mu)\left(\frac{a}{t}\right)^{2} k_{z}\right] A_{1}} \\
& {\left[\frac{1}{2 \beta^{2}} k_{x y}\right] A_{2}+\left[\frac{(1-\mu)}{\beta^{4}} k_{y}+\frac{1}{2 \beta^{2}}(1-2 \mu) k_{x y}+\frac{6}{\beta^{2}}(1-2 \mu)\left(\frac{a}{t}\right)^{2} k_{2 z}\right] A_{3}=\left[-\frac{6}{\beta^{2}}(1-2 \mu)\left(\frac{a}{t}\right)^{2} k_{Q}\right] A_{1}}
\end{aligned}
$$

Solving Equations 36 and 37 simultaneously gives:

$$
\begin{aligned}
& A_{2 R}=U A_{1} \\
& A_{2 Q}=V A_{1}
\end{aligned}
$$

Let:

$$
\begin{aligned}
& U=\frac{\left(r_{12} r_{23}-r_{13} r_{22}\right)}{\left(r_{12} r_{12}-r_{11} r_{22}\right)} \\
& V=\frac{\left(r_{12} r_{13}-r_{11} r_{23}\right)}{\left(r_{12} r_{12}-r_{11} r_{22}\right)}
\end{aligned}
$$

Where:

$$
\begin{aligned}
& r_{11}=(1-\mu) k_{x}+\frac{1}{2 \beta^{2}}(1-2 \mu) k_{x y}+6(1-2 \mu)\left(\frac{a}{t}\right)^{2} k_{z} \\
& r_{22}=\frac{(1-\mu)}{\beta^{4}} k_{y}+\frac{1}{2 \beta^{2}}(1-2 \mu) k_{x y}+\frac{6}{\beta^{2}}(1-2 \mu)\left(\frac{a}{t}\right)^{2} k_{2 z} \\
& r_{12}=r_{21}=\frac{1}{2 \beta^{2}} k_{x y} ; r_{13}=-6(1-2 \mu)\left(\frac{a}{t}\right)^{2} k_{z} ; r_{23}=r_{32}=-\frac{6}{\beta^{2}}(1-2 \mu)\left(\frac{a}{t}\right)^{2} k_{2 z}
\end{aligned}
$$

Minimizing Equation 33 with respect to $A_{l}$ gives:

$$
\frac{\partial \Pi}{\partial A_{1}}=\frac{D^{*} a b}{2 a^{4}}\left[6(1-2 \mu)\left(\frac{a}{t}\right)^{2}\left(\left[2 A_{1}+2 A_{2}\right] \cdot k_{z}+\frac{1}{\beta^{2}} \cdot\left[2 A_{1}+2 A_{3}\right] \cdot k_{2 Z}\right)-\frac{2 q a^{4} k_{h}}{D^{*}}\right]=0
$$

That is:

$$
6(1-2 \mu)\left(\frac{a}{t}\right)^{2}\left(\left[A_{1}+U A_{1}\right] \cdot k_{z}+\frac{1}{\beta^{2}} \cdot\left[A_{1}+V A_{1}\right] \cdot k_{2 z}\right)-\frac{q a^{4} k_{h}}{D^{*}}=0
$$

Factorizing Equations 46 and simplifying gives:

$$
\begin{aligned}
& 6(1-2 \mu)\left(\frac{a}{t}\right)^{2} A_{1}\left([1+U] \cdot k_{z}+\frac{1}{\beta^{2}} \cdot[1+V] \cdot k_{2 z}\right)=\frac{q a^{4} k_{h}}{D^{*}} \\
& T A_{1}=\frac{q a^{4} k_{h}}{D^{*}} \\
& A_{1}=\frac{q a^{4}}{D^{*}}\left(\frac{k_{h}}{T}\right)
\end{aligned}
$$

Where:

$$
T=6(1-2 \mu)\left(\frac{a}{t}\right)^{2} *\left(\left[1+G_{2}\right] \cdot k_{z}+\frac{1}{\beta^{2}} \cdot\left[1+G_{3}\right] \cdot k_{2 z}\right)
$$

\section{3- Numerical Analysis}

The analysis of a thick rectangular SSSS plate whose Poisson's ratio is 0.3 and carrying uniformly distributed load (including self-weight) presented. This is done by determining the deflection, $\mathrm{w}$ where $\mathrm{R}=0.5, \mathrm{Q}=0.5$ and $\mathrm{S}=0$; normal in-plane stresses $(\sigma x$ and $\sigma y)$, where $\mathrm{R}=0.5, \mathrm{Q}=0.5$ and $\mathrm{S}=0.5$; $\mathrm{x}$-y plane shear stress $\tau x y$ where $\mathrm{R}=0, \mathrm{Q}=0$ and $\mathrm{S}$ $=0.5 ; \mathrm{x}-\mathrm{z}$ plane shear stress $\tau \mathrm{xz}$ where $\mathrm{R}=0, \mathrm{Q}=0.5$ and $\mathrm{S}=0$. The trigonometric shape function as was obtained in the previous section is subjected to the rectangular SSSS plate boundary condition shown on Figure 3 for various aspect ratios and span-depth ratio. 


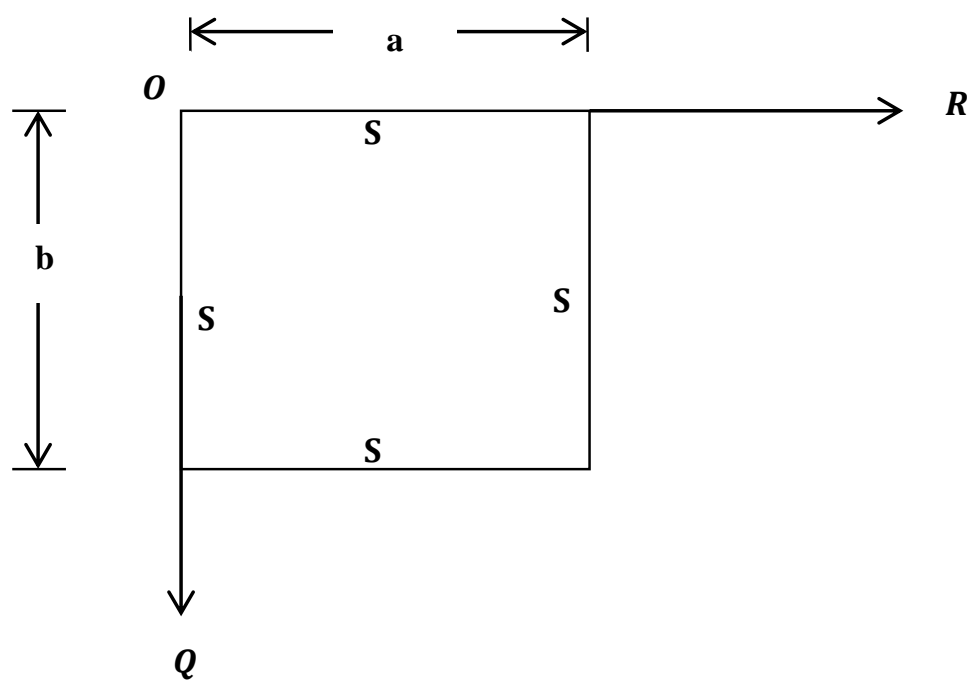

Figure 3. SSSS Rectangular Plate.

The deflection functions after satisfying the boundary conditions in trigonometric forms is given as:

$w=A_{1} \operatorname{Sin} \pi R \cdot \operatorname{Cos} \pi R$

Where:

$h=\operatorname{Sin} \pi R \cdot \operatorname{Cos} \pi R$

The stiffness coefficients for the trigonometric and polynomial deflection functions are presented on Table 1.

Table 1. Trigonometric form of stiffness coefficients of SSSS rectangular plate.

\begin{tabular}{cccccc}
\hline Deflection form & $k_{x}$ & $k_{x y}$ & $k_{y}$ & $k_{z}$ & $k_{2 z}$ \\
\hline \multirow{2}{*}{ Trigonometry } & $\frac{\pi^{4}}{4}$ & $\frac{\pi^{4}}{4}$ & $\frac{\pi^{4}}{4}$ & $\frac{\pi^{2}}{4}$ & $\frac{\pi^{2}}{4}$ \\
\hline
\end{tabular}

The displacements and stress can be defined in non-dimensional form in line with the work of Sayyad and Ghugal (2012) as:

$$
\begin{aligned}
& \bar{w}=\frac{100 \mathrm{Ew}}{q t \rho^{4}} \\
& \bar{u}=\frac{\mathrm{uE}}{q t \rho^{3}} \\
& \bar{v}=\frac{\mathrm{uE}}{q t \rho^{3}}
\end{aligned}
$$

That is:

$$
\overline{\sigma_{x}}=\frac{\sigma_{x}}{\mathrm{q} \rho^{2}}
$$

Similarly;

$$
\begin{aligned}
& \overline{\sigma_{y}}=\frac{\sigma_{y}}{\mathrm{q} \rho^{2}} \\
& \overline{\tau_{x y}}=\frac{\tau_{x y}}{\mathrm{q} \rho^{2}} \\
& \overline{\tau_{x z p}}=\frac{\tau_{x z p}}{\mathrm{q} \rho}
\end{aligned}
$$

Similarly;

$$
\tau_{y z}=\frac{\tau_{y z p}}{\mathrm{q} \rho}
$$

Using Equation 53 to 60, the non-dimensional stress elements of the plate is given as: 


$$
\begin{aligned}
\mathrm{w} & =1200\left(1-\mu^{2}\right) \bar{w} \\
\mathrm{u} & =12\left(1-\mu^{2}\right) \bar{u} \\
\mathrm{v} & =12\left(1-\mu^{2}\right) \bar{v} \\
\sigma_{x} & =12 \overline{\sigma_{x}} \\
\sigma_{y} & =12 \overline{\sigma_{y}} \\
\tau_{x y} & =12(1-\mu) \overline{\tau_{x y}} \\
\tau_{x z} & =12(1-\mu) \tau_{x z p}
\end{aligned}
$$

\section{4- Results and Discussions}

The result of displacements and stresses for the three dimensional isotropic plate and carrying a transverse load are presented in non-dimensional form in Tables 2 through 5. The non-dimensional maximum deflection and stresses at the given coordinate positions are presented in Tables 2, 3, 4 and 5 for the span-to-thickness ratios of 4, 10, 100 and 1000. Results obtained for maximum deflection and stresses compared and discussed with the corresponding results of CPT [5], FSDT [9], TSDT [25], HSDT [14], the exact elasticity solution for bidirectional bending of plates [20] and exact elasticity solution for pure bending analysis of plate [21]. The percentage error result of this particular theory with respect to past study is calculated using expressions presented in Table 6 .

Looking at the Tables, it shall be observed that as the span-depth ratio increases, the values of deflection and $\mathrm{x}-\mathrm{z}$ plane shear stress far to those obtained from the past studies using CPT \& RPT, and near to those exact elasticity theories. Hence, the closest measured as a percentage difference is $4.08 \%$ [21] while the farthest is $29.19 \%$ [5] at span-to-depth ratio of 10 for deflection and stresses at span-to-depth ratio of 4 respectively. The overall average percentage difference values of displacement and stress obtained by Present theory and those of CPT, RPT and 3D plate theory of all aspect ratios is $25.39 \%, 21.09 \%$ and $12.18 \%$ respectively. Out of $12.18 \%$ in 3D theory, $7.17 \%$ for the author in [21] and $17.18 \%$ for the author in [20] are discovered. This means that the analytical process [21] gives more accurate results than a numerical approach [20].

The classical plate theory and other higher order theories overestimate the results of in-plane displacement as compared to the present theory and those of other exact solution. The CPT and FSDT underestimate the deflection and stress for all the aspect ratios. The least average percentage difference for CPT and FSDT is 18.24\% at span-to-depth ratio of 100 , the value which is much to be ignored. Also, the refined plate theories overestimate the deflection and $\mathrm{x}-\mathrm{z}$ plane shear stress. For normal in-plane stresses it is observed that as span-to-depth ratio increases the recorded percentage difference increases. The least average percentage difference is $14.41 \%$ at span-to-depth ratio of 4 . This also confirms the coarseness of refined plate theories in the thick plate analysis. The central deflections and stresses predicted by the present theory are in close agreement with those of other exact elasticity solution $[20,21]$ for all the aspect ratios. The least average percentage difference for 3D theory is $4.08 \%$ at span-to-depth ratio of 10 . The implication is that classical plate theory and refined plate theories are quite coarse is for thick plate analysis. Hence, the need to use complete 3D (three-dimensional) plate analysis to ensure accuracy.

It is also observed that the values obtained from the models used herein almost coincide with the values from the RPT and CPT at a span - depth ratio of 100. This confirmed CPT which state that, thin plate is that which span-depth ratio is

\begin{tabular}{|c|c|c|c|c|c|c|}
\hline Scholars & Theories & $\mathbf{w}$ & $\overline{\sigma_{x}}$ & $\overline{\sigma_{y}}$ & $\overline{\tau_{\mathrm{xy}}}$ & $\overline{\tau_{\mathrm{xz}}}$ \\
\hline Present Study & $\begin{array}{l}\text { 3D exact plate theory } \\
\text { (trigonometric) }\end{array}$ & 4.4928 & 0.3571 & 0.3571 & -0.1524 & 0.1842 \\
\hline Pagno (1970) $[\mathrm{P}]$ & Elasticity plate theory & 5.6940 & 0.3070 & 0.3070 & - & 0.2067 \\
\hline Ibearugbulem et al. (2021) [I] & 3-D plate theory (Polynomial) & 4.8207 & 0.3832 & 0.3832 & -0.1635 & 0.1976 \\
\hline Onyeka et al. (2018) [O] & HSDT & 6.1553 & 0.3597 & 0.3597 & -0.2066 & 0.3907 \\
\hline Karama et al. (2003) [K] & TSDT & 6.1035 & 0.3452 & 0.3452 & -0.1859 & 0.3849 \\
\hline Mindlin (1951) [M] & FSDT & 5.6330 & 0.2870 & 0.2870 & 0.1951 & 0.3331 \\
\hline Kirchhoff (1850) [Kr] & CPT & 4.4360 & 0.2870 & 0.2870 & 0.1951 & 0.0000 \\
\hline
\end{tabular}
100 and above. Thus far, it has been seen that results previous authors using CPT and RPT underestimate or over predict the stresses in the plate structure which make their result far to those of 3D analysis. But plate analysis is a threedimensional problem which requires 3D analysis to achieve an exact solution. Being an analytical process, the 3D analysis presented herein is recommended by the authors for Engineers to begin the analysis of plates using the simple trigonometric 3D method of analysis of plate presented in this paper to ensure effective results.

Table 2. Non dimensional forms of displacement and stresses of SSSS plate at aspect ratio $b / a=1.0$ and $a / t=4$. 


\begin{tabular}{|c|c|c|c|c|c|c|}
\hline$\%$ Difference & Average $\%$ Difference & $\mathbf{w}$ & $\overline{\sigma_{x}}$ & $\overline{\sigma_{y}}$ & $\overline{\tau_{x y}}$ & $\overline{\boldsymbol{\tau}_{\mathrm{xz}}}$ \\
\hline$\%$ Diff between Present and $[\mathrm{P}]$ & 16.10 & 21.096 & 16.319 & - & - & 10.885 \\
\hline$\%$ Diff between Present and $[\mathrm{I}]$ & 6.80 & 6.8019 & 6.8111 & 6.8111 & 6.7890 & 6.7814 \\
\hline$\%$ Diff between Present and [O] & 22.40 & 27.009 & 0.7228 & 0.7228 & 26.234 & 52.854 \\
\hline$\%$ Diff between Present and $[\mathrm{K}]$ & 21.51 & 26.390 & 3.4473 & 3.4473 & 18.020 & 52.143 \\
\hline$\%$ Diff between Present and $[\mathrm{M}]$ & 27.14 & 20.241 & 24.425 & 24.425 & 21.886 & 44.701 \\
\hline$\%$ Diff between Present and $[\mathrm{Kr}]$ & 34.40 & 1.2804 & 24.425 & 24.425 & 21.886 & 100 \\
\hline
\end{tabular}

Table 3. Non dimensional forms of displacement and stresses of SSSS plate at aspect ratio $b / a=1.0$ and $a / t=10$.

\begin{tabular}{|c|c|c|c|c|c|c|}
\hline Scholars & Theories & $\mathbf{w}$ & $\overline{\sigma_{x}}$ & $\overline{\sigma_{\mathrm{y}}}$ & $\overline{\tau_{\mathrm{xy}}}$ & $\overline{\tau_{\mathrm{xz}}}$ \\
\hline Present Study & $\begin{array}{l}\text { 3D exact plate theory } \\
\text { (trigonometric) }\end{array}$ & 4.2245 & 0.3783 & 0.3783 & -0.1614 & 0.2326 \\
\hline Pagno (1970) [P] & Elasticity plate theory & 4.6390 & 0.2890 & 0.2890 & - & 0.2380 \\
\hline Ibearugbulem et al. (2021) []] & 3-D plate theory (Polynomial) & 4.4039 & 0.3944 & 0.3944 & -0.1683 & 0.2425 \\
\hline Onyeka et al. (2018) [O] & HSDT & 4.7738 & 0.3176 & 0.3176 & -0.1824 & 0.3818 \\
\hline Karama et al. (2003) [K] & TSDT & 4.7970 & 0.3243 & 0.3243 & -0.1746 & 0.3909 \\
\hline Mindlin (1951) [M] & FSDT & 4.6701 & 0.2870 & - & 0.1951 & 0.3331 \\
\hline Kirchhoff (1850) [Kr] & $\mathrm{CPT}$ & 4.4360 & 0.2870 & 0.2870 & 0.1950 & 0.4950 \\
\hline \% Difference & Average \% Difference & $\mathbf{w}$ & $\overline{\sigma_{\mathrm{x}}}$ & $\overline{\sigma_{y}}$ & $\overline{\tau_{\mathrm{xy}}}$ & $\overline{\bar{\tau}_{\mathrm{xz}}}$ \\
\hline$\%$ Diff between Present and [P] & 18.25 & 8.9351 & 30.900 & 30.900 & - & 2.2689 \\
\hline$\%$ Diff between Present and $[\mathrm{I}]$ & 4.08 & 4.0737 & 4.0822 & 4.0822 & 4.0998 & 4.0825 \\
\hline$\%$ Diff between Present and [O] & 24.69 & 11.507 & 19.112 & 19.112 & 11.513 & 39.078 \\
\hline$\%$ Diff between Present and [K] & 18.66 & 11.935 & 16.651 & 16.651 & 7.5601 & 40.496 \\
\hline$\%$ Diff between Present and $[\mathrm{M}]$ & 22.20 & 9.5416 & 31.812 & - & 17.273 & 30.171 \\
\hline$\%$ Diff between Present and [Kr] & 27.73 & 4.7678 & 31.812 & 31.812 & 17.231 & 53.010 \\
\hline
\end{tabular}

Table 4. Non dimensional forms of displacement and stresses of SSSS plate at aspect ratio of $b / a=1.0$ and $a / t=100$.

\begin{tabular}{|c|c|c|c|c|c|c|}
\hline Scholars & Theories & $\mathbf{w}$ & $\overline{\sigma_{\mathrm{x}}}$ & $\overline{\sigma_{\mathbf{y}}}$ & $\overline{\bar{\tau}_{\mathrm{xy}}}$ & $\overline{\tau_{\mathrm{xz}}}$ \\
\hline Present Study & $\begin{array}{l}\text { 3D exact plate theory } \\
\text { (trigonometric) }\end{array}$ & 3.8314 & 0.3536 & 0.3536 & -0.1503 & 0.2255 \\
\hline Pagno (1970) [P] & Elasticity plate theory & - & - & - & - & - \\
\hline Ibearugbulem et al. (2021) []] & 3-D plate theory (Polynomial) & 4.3032 & 0.3971 & 0.3971 & -0.1694 & 0.2533 \\
\hline Onyeka et al. (2018) [O] & HSDT & 4.5203 & 0.3099 & 0.3099 & -0.1780 & 0.3802 \\
\hline Karama et al. (2003) [K] & TSDT & 4.5460 & 0.3203 & 0.3203 & -0.1725 & 0.3909 \\
\hline Mindlin (1951) [M] & FSDT & - & - & - & - & - \\
\hline Kirchhoff (1850) [Kr] & $\mathrm{CPT}$ & 4.5201 & 0.3203 & 0.3203 & -0.1725 & 0.3909 \\
\hline \% Difference & Average \% Difference & $\mathbf{w}$ & $\overline{\sigma_{\mathrm{x}}}$ & $\overline{\sigma_{\mathrm{y}}}$ & $\overline{\tau_{\mathrm{xy}}}$ & $\overline{\tau_{\mathrm{xz}}}$ \\
\hline$\%$ Diff between Present and $[\mathrm{P}]$ & - & - & - & - & - & - \\
\hline$\%$ Diff between Present and $[\mathrm{I}]$ & 11.02 & 10.964 & 10.954 & 10.954 & 11.275 & 10.975 \\
\hline$\%$ Diff between Present and [O] & 19.94 & 15.240 & 14.101 & 14.101 & 15.562 & 40.689 \\
\hline$\%$ Diff between Present and $[\mathrm{K}]$ & 18.34 & 15.719 & 10.397 & 10.397 & 12.870 & 42.313 \\
\hline$\%$ Diff between Present and [M] & - & - & - & - & - & - \\
\hline$\%$ Diff between Present and [Kr] & 18.24 & 15.236 & 10.397 & 10.397 & 12.870 & 42.312 \\
\hline
\end{tabular}

Table 5. Non dimensional forms of displacement and stresses of SSSS plate at aspect ratio of $b / a=1.0$ and $a / t=1000$.

\begin{tabular}{ccccccc}
\hline Scholars & Theories & $\mathbf{w}$ & $\overline{\boldsymbol{\sigma}_{\mathbf{x}}}$ & $\overline{\boldsymbol{\sigma}_{\mathbf{y}}}$ & $\overline{\boldsymbol{\tau}_{\mathbf{x y}}}$ & $\overline{\boldsymbol{\tau}_{\mathbf{x z}}}$ \\
\hline Present Study & $\begin{array}{c}\text { 3D exact plate theory } \\
\text { (trigonometric) }\end{array}$ & 3.8314 & 0.3537 & 0.3537 & -0.1504 & 0.2257 \\
Pagno (1970) [P] & Elasticity plate theory & - & - & - & - \\
Ibearugbulem et al. (2021) [I] & 3-D plate theory (Polynomial) & 4.3021 & 0.3971 & 0.3971 & -0.1694 & 0.2534 \\
Onyeka et al. (2018) [O] & HSDT & 4.5178 & 0.3099 & 0.3099 & -0.1780 & 0.3802 \\
Karama et al. (2003) [K] & TSDT & 4.5435 & 0.3099 & 0.3099 & -0.1780 & 0.3802 \\
Mindlin (1951) [M] & FSDT & - & - & - & - \\
Kirchhoff (1850) [Kr] & CPT & 4.5201 & 0.3099 & 0.3099 & -0.1790 & 0.0000 \\
\hline
\end{tabular}




\begin{tabular}{|c|c|c|c|c|c|c|}
\hline$\%$ Difference & Average \% Difference & $\mathbf{w}$ & $\overline{\sigma_{x}}$ & $\overline{\sigma_{y}}$ & $\overline{\tau_{\mathrm{xy}}}$ & $\overline{\tau_{\mathrm{xz}}}$ \\
\hline$\%$ Diff between Present and $[\mathrm{P}]$ & - & - & - & - & - & - \\
\hline$\%$ Diff between Present and $[\mathrm{I}]$ & 6.76 & 10.941 & 0.3537 & 0.3537 & 11.216 & 10.931 \\
\hline$\%$ Diff between Present and [O] & 14.41 & 15.193 & 0.3537 & 0.3537 & 15.506 & 40.637 \\
\hline$\%$ Diff between Present and $[\mathrm{K}]$ & 14.50 & 15.673 & 0.3537 & 0.3537 & 15.506 & 40.637 \\
\hline$\%$ Diff between Present and [M] & - & - & - & - & - & - \\
\hline$\%$ Diff between Present and [Kr] & 26.38 & 15.236 & 0.3537 & 0.3537 & 15.978 & 100 \\
\hline
\end{tabular}

Table 6. Percentage difference summary of a rectangular square plate at varying span-depth ratio (a/t) from present and past studies.

\begin{tabular}{|c|c|c|c|c|c|c|}
\hline \multirow[b]{2}{*}{$\begin{array}{l}\text { Span-to depth } \\
\text { ratio }(a / t)\end{array}$} & \multicolumn{6}{|c|}{$\% D$ iff $=\frac{\text { Absolute difference betwee present and pasr value }}{\text { Past value }}$} \\
\hline & $\begin{array}{l}\text { \%Diff between } \\
\text { Present and P }\end{array}$ & $\begin{array}{l}\text { \%Diff between } \\
\text { Present and I }\end{array}$ & $\begin{array}{l}\text { \%Diff between } \\
\text { Present and } 0\end{array}$ & $\begin{array}{l}\text { \%Diff between } \\
\text { Present and } \mathrm{K}\end{array}$ & $\begin{array}{l}\text { \%Diff between } \\
\text { Present and M }\end{array}$ & $\begin{array}{l}\text { \%Diff between } \\
\text { Present and Kr }\end{array}$ \\
\hline 4 & 16.10 & 6.80 & 22.40 & 21.51 & 27.14 & 29.19 \\
\hline 10 & 18.25 & 4.08 & 24.69 & 18.66 & 22.20 & 27.73 \\
\hline 100 & - & 11.02 & 19.94 & 18.34 & - & 18.24 \\
\hline 1000 & - & 6.76 & 14.41 & 14.50 & - & 26.38 \\
\hline $\begin{array}{c}\text { Average \% } \\
\text { Difference }\end{array}$ & 17.18 & 7.17 & 20.36 & 18.25 & 24.67 & 25.39 \\
\hline \multirow{2}{*}{$\begin{array}{c}\text { Total \% } \\
\text { Difference }\end{array}$} & \multicolumn{2}{|c|}{12.18} & \multicolumn{3}{|c|}{21.09} & 25.39 \\
\hline & \multicolumn{6}{|c|}{19.55} \\
\hline
\end{tabular}

\section{5- Conclusion}

The analytical solution of the work presents an application of a three-dimensional static plate theory on the elastic bending of simply supported isotropic rectangular plate carrying a uniformly distributed load by developing an exact trigonometric displacement function. The processes involved in the formulation of kinematics relations and threedimensional constitutive relations using the elastic static theory of isotropic plate. The strain energy and external work done on the plate, the total potential energy equation of a thick rectangular plate using energy expression was developed from the 3-D constitutive relations and kinematic deformation. The energy equation which is later transformed into the equilibrium equation in terms of compatibility equations to determine the relation between the rotation and deflection. The governing equations were derived and solved in terms of trigonometric and polynomial shape function to get the exact deflection function. Thereafter, the total potential energy equation was minimized using the function of rotation and deflection to obtain their coefficient and stresses in the plate.

The numerical solution was presented and result comparison of the calculated stress and deflection values obtained showed that the classical theory and 2-D refined plate theories are quite coarse for thick plate analysis. CPT and RPT under-predict displacements, stresses and bending loads within the engineering admissible error (5\%) in relatively thick plates with span to thickness ratios within 4 and 10. It is concluded that the typical three-dimensional bending equation using trigonometric displacement functions developed to produce an exact solution and are therefore recommended for more efficient analysis of thick plate. Also, the stress obtained by this theory accomplished a decent distribution of the transverse shear through the thickness of the plate and satisfies the zero surface stress condition for an isotropic rectangular plate. The resultant displacement and stresses obtained by present work using trigonometric shear deformation theory agreed well with those of refined plate theory, but varied more with value of the CPT. This validates the efficacy of the present theory in the thick plate analysis. Thus, the partial change in the state and form of governing equations SSSS boundary conditions obtained are compatible and can be used with certainty in the analysis any category of rectangular plates.

\section{6- Declarations}

\section{6-1-Author Contributions}

Conceptualization, F.C. and B.O.; methodology, F.C.; software, F.C.; validation, F.C. and B.O.; formal analysis, F.C.; investigation, F.C.; resources, F.C.; data curation, F.C.; writing — original draft preparation, F.C.; writing - review and editing, F.C.; visualization, F.C.; supervision, F.C.; project administration, F.C.; funding acquisition, B.O. All authors have read and agreed to the published version of the manuscript.

\section{6-2-Data Availability Statement}

The data presented in this study are available in article. 


\section{6-3-Funding}

The authors received no financial support for the research, authorship, and/or publication of this article.

\section{6-4- Conflicts of Interest}

The authors declare that there is no conflict of interests regarding the publication of this manuscript. In addition, the ethical issues, including plagiarism, informed consent, misconduct, data fabrication and/or falsification, double publication and/or submission, and redundancies have been completely observed by the authors.

\section{7- References}

[1] Onyechere, I. C., O. M. Ibearugbulem, U. C. Anya, L. Anyaogu, and C. T. G. Awodiji. "Free-Vibration Study of Thick Rectangular Plates Using Polynomial Displacement Functions.” Saudi Journal of Engineering and Technology 05, no. 02 (2020): 73-80. doi:10.36348/sjet.2020.v05i02.006.

[2] Onyeka, F C, and O T Edozie. "Application of Higher Order Shear Deformation Theory in the Analysis of Thick Rectangular Plate." International Journal on Emerging Technologies 11, no. 5 (2020): 62-67.

[3] Timoshenko, Stephen P. Theory of Plates \& Shells. University Press (India) Limited, 1959.

[4] Timoshenko, S.P. and S. Woinowsky-krieger (1970). Theory of plates and shells, (2nd Ed.). Mc Graw-Hill Book Co. P.379, Singapore.

[5] Kirchhoff, G R. “U' 'ber Das Gleichgewicht and Die Bewe Gung Einer Elastschen Scheibe.” Journal f' Ur Die Reine Und Angewandte Mathematik 40 (1850): 51-88.

[6] Kirchhoff, G. “Ueber Die Schwingungen Einer Kreisförmigen Elastischen Scheibe.” Annalen Der Physik 157, no. 10 (1850): 258-64. doi:10.1002/andp.18501571005.

[7] Leissa, A. W. "The Free Vibration of Rectangular Plates." Journal of Sound and Vibration 31, no. 3 (1973): $257-93$. doi:10.1016/S0022-460X(73)80371-2.

[8] Reissner, Eric. "The Effect of Transverse Shear Deformation on the Bending of Elastic Plates.” Journal of Applied Mechanics 12, no. 2 (June 1, 1945): A69-A77. doi:10.1115/1.4009435.

[9] Mindlin, R. D. "Influence of Rotatory Inertia and Shear on Flexural Motions of Isotropic, Elastic Plates." Journal of Applied Mechanics 18, no. 1 (1951): 31-38. doi:10.1115/1.4010217.

[10] Nguyen, Hoang Nam, Tran Thi Hong, Pham Van Vinh, Nguyen Dinh Quang, and Do Van Thom. “A Refined Simple First-Order Shear Deformation Theory for Static Bending and Free Vibration Analysis of Advanced Composite Plates." Materials 12, no. 15 (2019): 2385. doi:10.3390/ma12152385.

[11] B.O., Mama, Nwoji C.U., Ike C. C., and Onah H.N. "Analysis of Simply Supported Rectangular Kirchhoff Plates by the Finite Fourier Sine Transform Method.” International Journal of Advanced Engineering Research and Science 4, no. 3 (2017): 28591. doi:10.22161/ijaers.4.3.44.

[12] Zenkour, Ashraf M. "Exact Mixed-Classical Solutions for the Bending Analysis of Shear Deformable Rectangular Plates." Applied Mathematical Modelling 27, no. 7 (2003): 515-34. doi:10.1016/S0307-904X(03)00046-5.

[13] I.I, Sayyad. "Bending and Free Vibration Analysis of Isotropic Plate Using Refined Plate Theory." Bonfring International Journal of Industrial Engineering and Management Science 3, no. 2 (2013): 40-46. doi:10.9756/bijiems.4390.

[14] Onyeka, F C, F O Okafor, and H N Onah. "Displacement and Stress Analysis in Shear Deformable Thick Plate.” International Journal of Applied Engineering Research 13, no. 11 (2018): 9893-9908.

[15] Festus, Onyeka, and Edozie Thompson Okeke. "Analytical Solution of Thick Rectangular Plate with Clamped and Free Support Boundary Condition Using Polynomial Shear Deformation Theory.” Advances in Science, Technology and Engineering Systems Journal 6, no. 1 (2021): 1427-39. doi:10.25046/aj0601162.

[16] Zhang, Pengchong, Chengzhi Qi, Hongyuan Fang, and Wei He. "Three Dimensional Mechanical Behaviors of In-Plane Functionally Graded Plates.” Composite Structures 241 (2020). doi:10.1016/j.compstruct.2020.112124.

[17] Liu, C. F., and Y. T. Lee. "Finite Element Analysis of Three-Dimensional Vibrations of Thick Circular and Annular Plates." Journal of Sound and Vibration 233, no. 1 (2000): 63-80. doi:10.1006/jsvi.1999.2791.

[18] Hashemi, S. H., S. Farhadi, and S. Carra. "Free Vibration Analysis of Rotating Thick Plates." Journal of Sound and Vibration 323, no. 1-2 (2009): 366-84. doi:10.1016/j.jsv.2008.12.007.

[19] Uymaz, B., and M. Aydogdu. "Three Dimensional Shear Buckling of FG Plates with Various Boundary Conditions." In Composite Structures, edited by A J M Ferreira, 96:670-82, 2013. doi:10.1016/j.compstruct.2012.08.031. 
[20] Pagano, N. J. “Exact Solutions for Rectangular Bidirectional Composites and Sandwich Plates.” Journal of Composite Materials 4, no. 1 (1970): 20-34. doi:10.1177/002199837000400102.

[21] Ibearugbulem, O M, U C Onwuegbuchulem, and C N Ibearugbulem. "Analytical Three-Dimensional Bending Analyses of Simply Supported Thick Rectangular Plate.” International Journal of Engineering Advanced Research (IJEAR) 3, no. 1 (2021): $27-45$.

[22] Onyeka, F C, and O T Edozie. "New Refined Shear Deformation Theory Effect on Non-Linear Analysis of a Thick Plate Using Energy Method.” Arid Zone Journal of Engineering, Technology \& Environment 17, no. 1 (2021): 121-140.

[23] Owus, M, O Lawrence, and C Ignatius. "Application of Shear Deformation Theory for Analysis of CCCS and SSFS Rectangular Isotropic Thick Plates.” Journal of Mechanical and Civil Engineering IOSR - JMCE 15, no. 5 (2018): 33-42.

[24] Onyeka, F C, F O Okafor, and Onah H.N. "Application of a New Trigonometric Theory in the Buckling Analysis of ThreeDimensional Thick Plate.” International Journal of Emerging Technologies 12, no. 1 (2021): 228-240.

[25] Karama, M., K. S. Afaq, and S. Mistou. "Mechanical Behaviour of Laminated Composite Beam by the New Multi-Layered Laminated Composite Structures Model with Transverse Shear Stress Continuity." International Journal of Solids and Structures 40, no. 6 (2003): 1525-46. doi:10.1016/S0020-7683(02)00647-9. 